\title{
ORIGINAL ARTICLE \\ Comorbidity and physical activity in people with paraplegia: a descriptive cross-sectional study
}

\author{
L Montesinos-Magraner ${ }^{1}$, P Serra-Añón ${ }^{2}$, X García-Massóo ${ }^{3}$, L Ramírez-Garcerán ${ }^{1}$, L-M González ${ }^{4}$ and \\ MÁ González-Viejo ${ }^{1}$
}

Study Design: Descriptive cross-sectional study.

Setting: The study was conducted in the Spinal Cord Injury Unit of the University Vall d'Hebron Hospital and in the Physical Education and Sports Department of the University of Valencia.

Objectives: The aim of this study was to quantify the presence of comorbidities in spinal cord injury (SCl) subjects who did or did not perform regular physical activity (PA) and to identify the relationship between PA and the level of comorbidity.

Methods: The sample consisted of patients with complete motor SCl (T2-T12), who were fitted with an accelerometer attached to the non-dominant wrist for a period of 1 week. The clinical and blood analytic variables were selected by an expert panel.

Results: In the exploratory analysis, we have found differences in the total number of pathologies between active and inactive patients, with fewer total pathologies in the active patient group. An association was found between the PA level and diabetes mellitus $\left(\chi_{1}^{2}=3.96 ; P=0.047 ; \phi=0.25\right)$. We also observed an association between the cardioprotector level of high-density lipoprotein (HDL)-cholesterol and PA level $\left(\chi_{1}^{2}=3.62 ; P=0.057 ; \phi=0.24\right)$.

Conclusions: Our results suggest that patients considered active showed lower total comorbidity than inactive patients and higher protection levels against developing cardiovascular comorbidity.

Spinal Cord (2018) 56, 52-56; doi:10.1038/sc.2017.90; published online 1 August 2017

\section{INTRODUCTION}

The normal ageing process combined with the long-term deterioration produced by spinal cord injury (SCI) compromises the patient's general health status and increases the risk of acquiring further disabilities. The decline in cardiovascular function as a result of ageing is more pronounced in people with SCI than in the general population. Moreover, the pathological conditions associated with SCI, such as hyperinsulinemia, obesity and high cholesterol, could aggravate cardiovascular diseases, ${ }^{1-3}$ which are now the first cause of death in the SCI population. In addition, those with complete SCI have abnormal heart rate responses and blood pressure as compared with their healthy peers, which indicates alterations of the autonomous system $^{4}$ and reduced lung capacity, also characteristic of SCI. ${ }^{5}$

As regards the metabolic system, the frequency of glucose intolerance is higher in people with SCI and could be the cause of the higher risk of premature diabetes mellitus, ${ }^{6}$ possibly aggravated by their greater body mass index and central obesity characteristics.

As physical activity (PA) can modulate some of these SCI alterations, it is a relevant factor in primary and secondary prevention of several metabolic and cardiovascular diseases associated with SCI. Indeed, the few epidemiological studies carried out on the SCI population have shown encouraging results in terms of PA. ${ }^{7-10}$ The recommendations relating to exercises designed to improve stamina and maximal oxygen consumption $\left(\mathrm{VO}_{2} \mathrm{max}\right)$ in people with $\mathrm{SCI}$ are not very different from those that have been established for the general population. ${ }^{11-13}$ These recommendations advise from three to five $20-60$-min sessions per week at an intensity of $50-80 \%$ of $\mathrm{VO}_{2}$ max. ${ }^{14}$

Few studies have evaluated the daily PA in this population and even fewer have attempted to quantify the PA and energy expenditure measured by an accelerometer during a 1-week period. Most of these studies used a questionnaire to ascertain the level of activity, ${ }^{15,16}$ and some monitored the subjects' heart rate and indirect calorimetry during activities performed in a laboratory. ${ }^{17,18}$

As we considered it important to explore the relationship between PA and health-related factors in SCI subjects, the aim of this study was to quantify the comorbidities in two groups of SCI subjects who either did or did not perform regular PA.

\section{MATERIALS AND METHODS}

\section{Participants}

A convenience sample of 67 SCI patients was recruited from the database of the Hospital de la Vall d'Hebrón and the Hospital La Fe de Valencia for a crosssectional study that lasted for a period of 3 months. All the participants had complete traumatic motor SCI with injury levels between T2 and T12 (American Spinal Injury Association Impairment Scale A) and all were full-time manual wheelchair users.

The exclusion criteria were as follows: psychiatric disorder that could interfere with participation, siringomyelia, nervous impairment in upper extremities, ischemic cardiac pathology, recent osteoporotic fracture, mechanical ventilator dependent, acute cancer process or recent ischial, sacral or trochanteric pressure ulcers.

${ }^{1}$ Spinal Cord Injury Unit, University Hospital Vall d'Hebron, Barcelona, Spain; ${ }^{2}$ Department of Physiotherapy, University of Valencia, Valencia, Spain; ${ }^{3}$ Didáctica de la Expresión Musical, Plástica y Corporal, University of Valencia, Valencia, Spain and ${ }^{4}$ Department of Physical Education and Sports, University of Valencia, Valencia, Spain Correspondence: Dr L Montesinos-Magraner, Spinal Cord Injury Unit, University Hospital Vall d'Hebron, Passeig de la Vall d'Hebron 119-129, 08035 Barcelona, Spain. E-mail: lluisa.montesinos@gmail.com

Received 4 September 2016; revised 22 June 2017; accepted 23 June 2017; published online 1 August 2017 
The epidemiological characteristics of the population are given in Table 1.

All the participants provided a written informed consent, all the procedures were conducted in accordance with the principles of the World Medical Association's Declaration of Helsinki and the protocols were approved by the ethical committee of the Vall d'Hebrón Hospital.

\section{Experimental procedure}

All the subjects were clinically examined by a physician and SCI rehabilitation specialist. The body mass index and blood pressure were obtained, and the subjects were asked whether they suffered urinary infections, constipation, dysreflexia symptoms and whether they were in need of bladder voiding. The activity monitor was then attached to their non-dominant wrist $t^{17}$ and instructions were given regarding its use. All the patients' clinical data were obtained from the database of each hospital.

\section{PA measurement}

An Actigraph Model GT3X (Manufacturing Technology Inc., Fort Walton Beach, FL, USA) was used to measure PA by means of the accelerometer worn by the patients. The Actigraph was initialized using $30 \mathrm{~Hz}$ frequency, and the data were transformed into counts. $\mathrm{seg}^{-1}$. After 1 week, the participants returned the accelerometer to the hospital. Matlab R2010a (Mathworks Inc., Natick, MA, USA) software was used for preprocessing, segmentation and feature extraction from the signals. All the data over 5000 counts.seg $^{-1}$ were considered not to have been generated by the subjects and were removed, and any periods of 20 consecutive minutes without registrations were not considered valid. The activity records were considered valid if at least $10 \mathrm{~h}$ per day had been obtained in 4 days, of which 3 were during the week and 1 at the weekend.

The mathematical model developed by García-Massó et al. was used to analyze the PA. ${ }^{17}$ This model, using indirect calorimetry as gold standard, showed an $r$-value of 0.86 and a root mean square error of $2.23 \mathrm{ml} \mathrm{kg}^{-1} \mathrm{~min}^{-1}$. The PA levels were divided into sedentary (that is, $<1.5$ Metabolic equivalents (METS)), low (that is, 1.5-2.99 METS), moderate (that is, 3-5.99 METS) and vigorous (that is, $>6$ METS).

In accordance with the literature, ${ }^{15,19}$ the sample was divided into two groups: the subjects who performed at least $60 \mathrm{~min}$ of PA per week at the moderate-vigorous level were considered active $(n=37)$ and those who did less than 60 min were considered inactive $(n=30)$.

Table 1 Participants' clinical profile

\begin{tabular}{|c|c|c|c|c|}
\hline & Inactive $(\mathrm{n}=30)$ & Active $(n=37)$ & $\begin{array}{l}\text { Mean between-group } \\
\text { difference with } 95 \% \mathrm{Cl}\end{array}$ & P-value \\
\hline \multicolumn{5}{|l|}{ Gender } \\
\hline Male & $20(66.7)$ & 31 (83.8) & - & - \\
\hline Female & $10(33.3)$ & $6(16.2)$ & - & - \\
\hline \multicolumn{5}{|c|}{ Neurological level } \\
\hline$\leqslant T 6$ & $14(46.7)$ & $21(56.8)$ & - & - \\
\hline$>\mathrm{T} 6$ & $16(53.3)$ & $16(43.2)$ & - & - \\
\hline Age (years) & $50.63(14.12)$ & $43.3(12.16)$ & $7.34(0.92$ to 13.75$)$ & 0.02 \\
\hline Weight (kg) & 73.85 (12.78) & $70.81(13.0)$ & $3.04(-3.29$ to 9.37$)$ & 0.34 \\
\hline Height (m) & $1.7(0.08)$ & $1.73(0.1)$ & $-3.37(-7.89$ to 1.16$)$ & 0.14 \\
\hline BMI $\left(\mathrm{kg} \mathrm{m}^{-2}\right)$ & $25.67(4.48)$ & $23.57(3.51)$ & $2.10(0.15$ to 4.05$)$ & 0.03 \\
\hline $\begin{array}{l}\text { Time since } \\
\text { injury (years) }\end{array}$ & $15.77(11.71)$ & $17.76(11.6)$ & $-1.99(-7.71$ to 3.73$)$ & 0.48 \\
\hline
\end{tabular}

Abbreviations: BMI, body mass index; $\mathrm{Cl}$, confidence interval; T6, 6th thoracic level. Data are expressed as mean (s.d.) or mean $(95 \% \mathrm{Cl})$. For gender and neurological level, the number of participants is shown $N(\%)$

\section{Medical data}

A panel of experts selected the medical variables following the European Cooperation Office (EuropeAid) recommendations, after a review of the main scientific databases (for example, WOS, Pubmed, Cochrane and so on).

The variables selected were as follows: neurological level, time from injury, hypertension, dyslipidemia, diabetes mellitus, cardiological or pulmonary diseases, metabolic diseases, vascular problems, psychological disorders, fractures and other musculoskeletal pathologies, allergies, pressure ulcers and urinary infections that required admission to hospital. The subject's lipid profile was measured to assess the risk of cardiovascular disease. Total cholesterol (TC) and triglycerides (TGs) were determined using standardized enzymatic procedures. High-density lipoprotein (HDL) and low-density lipoprotein (LDL) were selectively precipitated and the TC/HDL ratio was calculated. Total proteins and albumin were studied.

The metabolic syndrome was then assessed following the criteria of the American Association of Clinical Endocrinologists. ${ }^{20}$

\section{Statistical analysis}

The statistical analyses were performed on SPSS 20.0 software (IBM Corporation, Armonk, NY, USA). The mean and s.d. were used to describe data. Although the main goal of this study was descriptive, we also explored the possible differences between physically active and non-active people. To this purpose, the mean differences between groups and the $95 \%$ confidence interval were computed. Further, the Mann-Whitney $U$-test was conducted. Categorical variables were tested using the $\chi^{2}$-test and effect size $\left(\phi=\sqrt{\chi^{2} / N}\right) \cdot{ }^{21}$ Besides, the odds ratios (ORs) were reported.

\section{RESULTS}

\section{General results of the participants}

The clinical profiles of the participants are shown in Table 1. The active group was slightly younger and taller and showed a lower BMI than the inactive group.

The mean weekly time for each PA level and sedentary activity level of all the participants can be seen in Table 2. As we had expected, the active patients performed more minutes of light, moderate, vigorous, moderate-to-vigorous activity and had higher average METs than the inactive patients. In fact, this difference is greater in METs and moderate-to-vigorous weekly PA variables.

The most frequent comorbidities associated with SCI were as follows: urinary tract infections requiring hospital admission (52\%), pressure ulcer (39\%) and dyslipidemia (22\%; see Figure 1).

\section{PA and comorbidity}

We found differences between the active and inactive groups in the total number of pathologies, with fewer comorbidities in the active group. Each pathology was analyzed separately and a statistical association was found between PA group and diabetes mellitus $\left(\chi_{1}^{2}=3.96 ; P=0.047 ; \phi=0.25\right)$. On the basis of the OR, the active subjects were 7.2 times less likely to suffer non-insulin-dependent diabetes mellitus than inactive subjects.

The metabolic syndrome was assessed through American Association of Clinical Endocrinologists criteria. Sixty-three percent of the inactive patients presented two or more risk factors for metabolic syndrome, in contrast to the $59 \%$ of the active patients who presented none or only one risk factor.

Blood variable values were similar in both groups (Table 3 ). The HDL-cholesterol $>45 \mathrm{mg} \mathrm{dl}^{-1}$ was associated with a higher PA level $\left(\chi_{1}^{2}=3.62 ; P=0.057 ; \phi=0.24\right)$. On the basis of the OR, the odds of a subject having more than $45 \mathrm{mg} \mathrm{dl}^{-1}$ of $\mathrm{HDL}$ were 2.86 times higher if they were physically active than inactive. 
Table 2 Daily physical activity of participants and sedentary behavior

\begin{tabular}{|c|c|c|c|c|}
\hline & Inactive $(\mathrm{n}=30)$ & Active $(n=37)$ & Mean between-group difference with $95 \% \mathrm{Cl}$ & P-value \\
\hline Sedentary (min per day) & $631.05(184.25)$ & $653.21(192.6)$ & $-22.16(-114.85$ to 70.54$)$ & 0.64 \\
\hline Moderate (min per day) & $3.86(3.01)$ & $26.75(19.64)$ & $-22.89(-29.52$ to -16.26$)$ & $<0.001$ \\
\hline Vigorous (min per day) & $0.01(0.04)$ & $0.22(0.54)$ & $-0.21(-0.39$ to -0.03$)$ & 0.04 \\
\hline Moderate-to-vigorous (min per day) & $3.87(3.0)$ & $26.97(19.96)$ & $-23.10(-29.83$ to -16.37$)$ & $<0.001$ \\
\hline
\end{tabular}

Abbreviation: $\mathrm{Cl}$, confidence interval.

Data are expressed as mean (s.d.) or mean $(95 \% \mathrm{Cl})$.

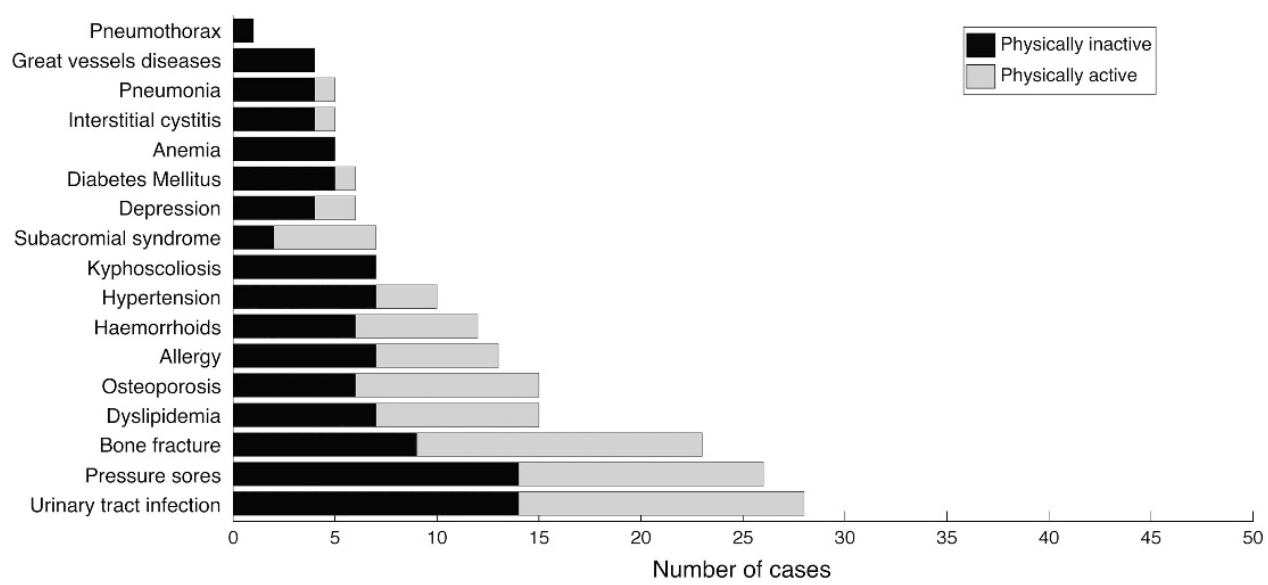

Figure 1 Number of cases of each comorbidity for active and inactive subjects.

Table 3 Blood analytical variables for lipid profile, total proteins and albumin, stratifying between active and inactive group

\begin{tabular}{|c|c|c|c|c|}
\hline & Inactive $(\mathrm{n}=30)$ & Active $(n=37)$ & Mean between-group difference with $95 \% \mathrm{Cl}$ & P-value \\
\hline HDL-C (mg dl-1) & $49.36(7.7)$ & $50.64(9.58)$ & $-1.28(-5.59$ to 3.03$)$ & 0.33 \\
\hline Triglycerides (mg dl-1) & $133.12(50.27)$ & $120.86(61.46)$ & $12.26(-15.58$ to 40.10$)$ & 0.23 \\
\hline Proteins $\left(\mathrm{g} \mathrm{dl}^{-1}\right)$ & $7.14(0.37)$ & $10.72(15.72)$ & $-3.58(-8.82$ to 1.66$)$ & 0.83 \\
\hline Albumin $\left(\mathrm{g} \mathrm{dl}^{-1}\right)$ & $4.33(0.27)$ & $4.31(0.37)$ & $0.01(-0.15$ to 0.17$)$ & 0.70 \\
\hline
\end{tabular}

Abbreviations: $\mathrm{Cl}$, confidence interval; HDL-C, high-density lipoprotein cholesterol; LDL-C, low-density lipoprotein cholesterol; TC, total cholesterol.

Data are expressed as mean (s.d.) or mean $(95 \% \mathrm{Cl})$.

\section{DISCUSSION}

The results obtained suggest that the subjects with an inactive life-style suffered a higher number of SCI-associated comorbidities than active SCI subjects. Although the study design used could not establish causality, an association was discovered between performing PA and suffering from diabetes mellitus. In addition, there were more patients with metabolic syndrome in the inactive group. A level above $45 \mathrm{mg} \mathrm{dl}^{-1} \mathrm{HDL}$, which is considered cardioprotective, could be associated with PA.

We found that a high percentage of the paraplegic population suffered from comorbidities associated with SCI. The most frequent of these were as follows: urinary infection requiring hospital admission $(52 \%)$, pressure ulcers $(39 \%)$ and dyslipidemia (22\%). These results are similar to those obtained for this population in other studies, ${ }^{22-24}$ for example, Brinkhof et al. found a prevalence of the urinary tract infection and pressure ulcers of $59 \%$ and $34 \%$, respectively. ${ }^{25}$

The average PA value was 1.51 METs, which is a relatively low level of energy expenditure. The patients were involved in low- or very-low- intensity activities most of the time, although $55 \%$ of the subjects fulfilled the PA recommendations to be considered physically active (at least 60 min activity per week of moderate-to-vigorous intensity).

Diabetes and the metabolic syndrome have been strongly associated with cardiovascular diseases. ${ }^{26,27}$ In 1994, Bauman and Spungen ${ }^{28}$ identified higher glucose and insulin blood levels in an SCI population than in a control group. Insulin sensitivity has been observed in twothirds of the tetraplegic population and in 50\% of paraplegics. Similarly, Lee et al. detected the metabolic syndrome in $23 \%$ of people with SCI, approximately double the incidence in the control group stratified by gender and age, ${ }^{29}$ in agreement with the work done by Jones et al. ${ }^{30}$ This suggests that there is a relationship between metabolic syndrome and SCI.

PA has been found to act as a protecting factor against the metabolic syndrome. ${ }^{31-34}$ Manns et al. found that paraplegic patients with a low level of cardiorespiratory fitness who did not exercise had a higher fasting glucose blood level, lower HDL-cholesterol levels and a larger waist circumference. ${ }^{32}$ The authors estimated cardiorespiratory 
fitness by measuring $\mathrm{VO}_{2}$ max during cardiopulmonary exercise testing with arm cycling and a self-assessment questionnaire. One possible mechanism may be due to premature tissue ageing associated with low levels of the insulin-like growth factor 1 (IGF-1) hormone and other growth factors. ${ }^{28}$ Inactivity involves a higher physiopathological risk of suffering sarcopenia, hyperglycemia, diabetes and cardiovascular diseases. Although we could not find any relationship between PA and the metabolic syndrome, this may be possible in future studies with a higher sample size.

The relationship between an altered lipid profile and having diabetes or cardiovascular disease has already been well established. ${ }^{35}$ Some studies have found higher LDL cholesterol and TC levels and lower HDL-cholesterol levels after SCI than in the non-disabled population. ${ }^{26,28,32,36,37}$ In line with the findings of other studies ${ }^{31,37}$ we did not find any relationship between the TC or LDL cholesterol level and physically active subjects. Although inactive paraplegics presented pathological TG levels (10\%), we did not find a relationship between these two factors. In the able-bodied population higher cholesterol and TG levels may be modified by PA and dieting. ${ }^{35}$ There is also a strong relationship between time from SCI and a high lipid profile in the SCI population, ${ }^{38}$ which suggests that the metabolic changes and physical inactivity associated with SCI may have significant consequences for their lipid profile.

On the other hand, the more active patients had slightly higher HDL-cholesterol levels. The SCI subjects who exercised for 60 min per week (with moderate-to-vigorous intensity) were 2.86 times more likely to present HDL-cholesterol in the cardioprotective range (over $45 \mathrm{mg} \mathrm{dl}^{-1}$ ). In agreement with our findings, Groot et al. ${ }^{37}$ found a significant relationship between higher PA levels and higher HDLcholesterol, but not in TC, LDL cholesterol and TG. Brenes et al. $^{39}$ used a questionnaire to ascertain activity level and found significantly lower HDL-cholesterol $\left(34.2 \mathrm{mg} \mathrm{dl}^{-1}\right)$ in 66 sedentary paraplegics as compared with 22 complete SCI subjects with athletic inclinations $\left(47.1 \mathrm{mg} \mathrm{dl}^{-1}\right)$.

Some studies measured daily PA solely by means of questionnaires, or only considered practising athletes as the active SCI population, and thus were not representative of the total SCI population. To our knowledge, only Nooijen et al. ${ }^{34}$ studied lipid profile and PA by accelerometry for two consecutive days. In this study, with a mix of paraplegics and tetraplegics, of which $72 \%$ had complete SCI, a significant relationship was found between higher TG levels and physical inactivity.

In the present study, we considered active patients as those who performed at least $60 \mathrm{~min}$ of moderate-to-vigorous PA per week, and this population had significantly higher HDL-cholesterol (more than $45 \mathrm{mg} \mathrm{dl}^{-1}$ ), which suggests that this PA level performed weekly could raise cardioprotective HDL-cholesterol levels.

Regarding diabetes, Cragg et al. ${ }^{40}$ found that the OR of Type 2 diabetes was 2.52 times greater in individuals with SCI versus individuals without SCI (95\% CI 1.81-3.52). Buchholz et al. ${ }^{7}$ in a sample of SCI found that the subjects who performed at least $25 \mathrm{~min}$ of physical exercise per day had lower insulin resistance (10\%) than inactive subjects (33\%). Although we found a lower incidence of Type 2 diabetes than other studies in the literature, there is a relationship between being considered inactive and suffering diabetes after SCI. In our study, the patients considered inactive presented a 7.2 times higher risk of getting Type 2 diabetes than active patients.

One mechanism could be explained by the relationship between sarcopenia, present in the SCI population, and insulin resistance. ${ }^{41}$ Moreover, as the SCI population have an altered autonomous nervous system and vascular system, this could be responsible for the higher metabolism dysfunction. ${ }^{40}$

The primary limitation of the present study is the small number of subjects in the sample, which means a Type II error could have been committed and further associations may not have been detected between PA and the comorbidities studied. Secondly, the age difference between groups (being younger the active people with SCI) could have influenced comorbidity as well as PA. In addition, it should be stressed that the grouping criterion used in this study (that is, 60 min per week of physical exercise) is extensively documented in studies in which the questionnaires are used to assess the PA but not in those whose measurement system is based on accelerometer devices.

At a practical level, further data need to be acquired in observational studies to reach epidemiological conclusions transferrable to the SCI population. Experimental studies with a higher control of confounding variables are also needed in order to establish causal relationships.

\section{CONCLUSIONS}

Our results suggest that active people with SCI present lower total comorbidity than inactive people with SCI. In addition, the patients considered active showed improved protection against developing cardiovascular comorbidity due to higher levels of HDL-cholesterol in the cardioprotective range. Our exploratory analysis showed that the active SCI population was also found to have a lower risk of contracting Type 2 diabetes.

\section{CONFLICT OF INTEREST}

The authors declare no conflict of interest.

\section{ACKNOWLEDGEMENTS}

XG-M gratefully acknowledges the support of the University of Valencia under Project UV-INV-PRECOMP13-115364 to acquire the research equipment used in this study. LMG gratefully acknowledges the support of the Ministerio de Economía, Industria y Competitividad under Project DEP2015-69692-P.

1 Bauman WA, Spungen AM. Carbohydrate and lipid metabolism in chronic spinal cord injury. J Spinal Cord Med 2001; 24: 266-277.

2 Gerhart KA, Bergstrom E, Charlifue SW, Menter RR, Whiteneck GG. Long-term spinal cord injury: functional changes over time. Arch Phys Med Rehabil 1993; 74. 1030-1034

3 Washburn RA, Figoni SF. High density lipoprotein cholesterol in individuals with spina cord injury: the potential role of physical activity. Spinal Cord 1999; 37: 685-695.

4 Hubli M, Gee CM, Krassioukov AV. Refined assessment of blood pressure instability after spinal cord injury. Am J Hypertens 2015; 28: 173-181.

5 Biering-Sørensen F, Jennum P, Laub M. Sleep disordered breathing following spinal cord injury. Respir Physiol Neurobiol 2009; 169: 165-170.

6 Lavela SL, Weaver FM, Goldstein B, Chen K, Miskevics S, Rajan S et al. Diabetes mellitus in individuals with spinal cord injury or disorder. J Spinal Cord Med 2006; 29: 387-395.

7 Buchholz AC, Martin Ginis KA, Bray SR, Craven BC, Hicks AL, Hayes KC et al. Greater daily leisure time physical activity is associated with lower chronic disease risk in adults with spinal cord injury. Appl Physiol Nutr Metab Physiol 2009; 34: 640-647.

8 Hetz SP, Latimer AE, Buchholz AC, Martin Ginis KA. Increased participation in activities of daily living is associated with lower cholesterol levels in people with spinal cord injury. Arch Phys Med Rehabil 2009; 90: 1755-1759.

9 Manns PJ, Chad KE. Determining the relation between quality of life, handicap, fitness, and physical activity for persons with spinal cord injury. Arch Phys Med Rehabil 1999; 80: 1566-1571

10 Slater D, Meade MA. Participation in recreation and sports for persons with spinal cord injury: review and recommendations. NeuroRehabilitation 2004; 19: 121-129.

11 Glaser RM. Functional neuromuscular stimulation. Exercise conditioning of spinal cord injured patients. Int J Sports Med 1994; 15: 142-148.

12 Jacobs PL, Nash MS. Exercise recommendations for individuals with spinal cord injury. Sports Med Auckl NZ 2004; 34: 727-751.

13 Taylor AW, McDonell E, Brassard L. The effects of an arm ergometer training programme on wheelchair subjects. Paraplegia 1986; 24: 105-114. 
14 Guyatt GH, Naylor CD, Juniper E, Heyland DK, Jaeschke R, Cook DJ. Users' guides to the medical literature. XII. How to use articles about health-related quality of life. Evidence-Based Medicine Working Group. JAMA 1997; 277: 1232-1237.

15 Ginis KAM, Latimer AE, Arbour-Nicitopoulos KP, Buchholz AC, Bray SR, Craven BC et al. Leisure time physical activity in a population-based sample of people with spinal cord injury part I: demographic and injury-related correlates. Arch Phys Med Rehabil 2010; 91: 722-728.

16 WHO. Obesity: preventing and managing the global epidemic. Report of a WHO consultation. World Health Organ Tech Rep Ser 2000; 894: 1-253.

17 García-Massó X, Serra-Añó P, García-Raffi LM, Sánchez-Pérez EA, López-Pascual J, Gonzalez LM. Validation of the use of Actigraph GT3X accelerometers to estimate energy expenditure in full time manual wheelchair users with spinal cord injury. Spinal Cord 2013; 51: 898-903.

18 Hiremath SV, Ding D, Farringdon J, Cooper RA. Predicting energy expenditure of manual wheelchair users with spinal cord injury using a multisensor-based activity monitor. Arch Phys Med Rehabil 2012; 93: 1937-1943.

19 Hicks AL, Martin Ginis KA, Pelletier CA, Ditor DS, Foulon B, Wolfe DL. The effects of exercise training on physical capacity, strength, body composition and functional performance among adults with spinal cord injury: a systematic review. Spinal Cord 2011; 49: 1103-1127.

20 Grundy SM, Brewer HB, Cleeman JI, Smith SC, Lenfant C, National Heart, Lung, and Blood Instituteet al. Definition of metabolic syndrome: report of the National Heart, Lung, and Blood Institute/American Heart Association conference on scientific issues related to definition. Arterioscler Thromb Vasc Biol 2004; 24: e13-e18.

21 Fritz CO, Morris PE, Richler JJ. Effect size estimates: current use, calculations, and interpretation. J Exp Psychol Gen 2012; 141: 2.

22 Anson CA, Shepherd C. Incidence of secondary complications in spinal cord injury. Int $J$ Rehabil Res 1996; 19: 55-66.

23 Charlifue S, Lammertse DP, Adkins RH. Aging with spinal cord injury: changes in selected health indices and life satisfaction. Arch Phys Med Rehabil 2004; 85: 1848-1853.

24 Walter JS, Sacks J, Othman R, Rankin AZ, Nemchausky B, Chintam R et al. A database of self-reported secondary medical problems among VA spinal cord injury patients: its role in clinical care and management. J Rehabil Res Dev 2002; 39: 53-61.

25 Brinkhof MWG, Al-Khodairy A, Eriks-Hoogland I, Fekete C, Hinrichs T, Hund-Georgiadis M et al. Health conditions in people with spinal cord injury: Contemporary evidence from a population-based community survey in Switzerland. J Rehabil Med 2016; 48: 197-209.

26 Guerrero-Romero F, Rodríguez-Morán M. Relation of C-reactive protein to features of the metabolic syndrome in normal glucose tolerant, impaired glucose tolerant, and newly diagnosed type 2 diabetic subjects. Diabetes Metab 2003; 29: 65-71.

27 Ridker PM, Buring JE, Cook NR, Rifai N. C-reactive protein, the metabolic syndrome, and risk of incident cardiovascular events: an 8-year follow-up of 14719 initially healthy American women. Circulation 2003; 107: 391-397.
28 Bauman WA, Spungen AM. Disorders of carbohydrate and lipid metabolism in veterans with paraplegia or quadriplegia: a model of premature aging. Metabolism 1994; 43: 749-756.

29 Lee MY, Myers J, Hayes A, Madan S, Froelicher VF, Perkash I et al. C-reactive protein, metabolic syndrome, and insulin resistance in individuals with spinal cord injury. J Spinal Cord Med 2005; 28: 20-25.

30 Jones LM, Legge M, Goulding A. Factor analysis of the metabolic syndrome in spinal cord-injured men. Metabolism 2004; 53: 1372-1377.

31 Liang H, Chen D, Wang Y, Rimmer JH, Braunschweig CL. Different risk factor patterns for metabolic syndrome in men with spinal cord injury compared with ablebodied men despite similar prevalence rates. Arch Phys Med Rehabil 2007; 88: 1198-1204.

32 Manns PJ, McCubbin JA, Williams DP. Fitness, inflammation, and the metabolic syndrome in men with paraplegia. Arch Phys Med Rehabil 2005; 86: 1176-1181.

33 Myers J, Lee M, Kiratli J. Cardiovascular disease in spinal cord injury: an overview of prevalence, risk, evaluation, and management. Am J Phys Med Rehabil Assoc Acad Physiatr 2007; 86: 142-152.

34 Nooijen CFJ, de Groot S, Postma K, Bergen MP, Stam HJ, Bussmann JBJ et al. A more active lifestyle in persons with a recent spinal cord injury benefits physical fitness and health. Spinal Cord 2012; 50: 320-323.

35 Expert Panel on Detection, Evaluation, and Treatment of High Blood Cholesterol in Adults. Executive Summary of The Third Report of The National Cholesterol Education Program (NCEP) Expert Panel on Detection, Evaluation, And Treatment of High Blood Cholesterol In Adults (Adult Treatment Panel III). JAMA 2001; 285: 2486-2497.

36 Bauman WA, Adkins RH, Spungen AM, Waters RL. The effect of residual neurological deficit on oral glucose tolerance in persons with chronic spinal cord injury. Spinal Cord 1999; 37: 765-771.

37 de Groot S, Post MW, Snoek GJ, Schuitemaker M, van der Woude LH. Longitudinal association between lifestyle and coronary heart disease risk factors among individuals with spinal cord injury. Spinal Cord 2013; 51: 314-318.

38 Moussavi RM, Ribas-Cardus F, Rintala DH, Rodriguez GP. Dietary and serum lipids in individuals with spinal cord injury living in the community. J Rehabil Res Dev 2001; 38: 225-233.

39 Brenes G, Dearwater S, Shapera R, LaPorte RE, Collins E. High density lipoprotein cholesterol concentrations in physically active and sedentary spinal cord injured patients. Arch Phys Med Rehabil 1986; 67: 445-450.

40 Cragg JJ, Noonan VK, Dvorak M, Krassioukov A, Mancini GBJ, Borisoff JF. Spinal cord injury and type 2 diabetes: results from a population health survey. Neurology 2013; 81: 1864-1868.

41 Srikanthan P, Hevener AL, Karlamangla AS. Sarcopenia exacerbates obesity-associated insulin resistance and dysglycemia: findings from the National Health and Nutrition Examination Survey III. PLOS ONE 2010; 5: e10805. 